\title{
Review
}

Cardiovascular Risk/Epidemiology

Diabetes Metab J 2021;45:492-501

https://doi.org/10.4093/dmj.2020.0262

pISSN 2233-6079 · eISSN 2233-6087

DIABET\&S \& METABOLISM JOURNAL

\section{Management of Cardiovascular Risk in Perimenopausal Women with Diabetes}

\author{
Catherine Kim \\ Departments of Medicine, Obstetrics \& Gynecology, and Epidemiology, University of Michigan, Ann Arbor, MI, USA
}

Cardiovascular disease is the primary cause of mortality in women and men with diabetes. Due to age and worsening of risk factors over the menopausal transition, risk of coronary heart disease events increases in postmenopausal women with diabetes. Randomized studies have conflicted regarding the beneficial impact of estrogen therapy upon intermediate cardiovascular disease markers and events. Therefore, estrogen therapy is not currently recommended for indications other than symptom management. However, for women at low risk of adverse events, estrogen therapy can be used to minimize menopausal symptoms. The risk of adverse events can be estimated using risk engines for the calculation of cardiovascular risk and breast cancer risk in conjunction with screening tools such as mammography. Use of estrogen therapy, statins, and anti-platelet agents can be guided by such calculators particularly for younger women with diabetes. Risk management remains focused upon lifestyle behaviors and achieving optimal levels of cardiovascular risk factors, including lipids, glucose, and blood pressure. Use of pharmacologic therapies to address these risk factors, particularly specific hypoglycemic agents, may provide some additional benefit for risk prevention. The minimal benefit for women with limited life expectancy and risk of complications with intensive therapy should also be considered.

Keywords: Cardiovascular diseases; Coronary diseases; Diabetes mellitus; Heart disease risk factors

\section{INTRODUCTION}

The menopausal transition and postmenopause represent periods of increased cardiovascular disease (CVD) risk for women. This increased risk is partially explained by advancing age: levels of blood pressure and glucose as well as non-traditional risk factors rise linearly with age during the menopausal transition [1]. Increased risk may also be partially attributed to the hormonal changes of the transition: low-density lipoprotein cholesterol (LDL-C) levels rise precipitously in the year before and the year after the final menstrual period (FMP) [1]. However, estrogen-based therapies do not appear to minimize CVD events during this window, and data for intermediate outcomes is mixed $[2,3]$. These data suggest that estrogenbased therapies can be used cautiously to relieve menopausal symptoms, but likely have minimal benefits for chronic disease prevention [4]. Thus, for women with diabetes, careful monitoring and treatment of blood pressure, lipids, and glucose in the peri- and postmenopause remain the mainstay of risk reduction for CVD morbidity and mortality.

In this review, I describe changes in CVD risk factors that occur during the menopausal transition, followed by data on the prevalence of CVD in relation to menopause. Next, I review briefly the studies examining the impact of estrogen therapy upon CVD outcomes and intermediate markers of atherosclerosis including coronary artery calcification (CAC) and carotid intima media thickness (cIMT). I discuss the use of risk engines that can be used to inform decisions regarding estrogen in newly postmenopausal women with diabetes; such risk engines focus upon risk of breast cancer as well as CVD outcomes. Finally, I summarize briefly the recommendations for risk factor targets and specific pharmacologic agents recom-
Corresponding author: Catherine Kim (D) https://orcid.org/0000-0001-9237-0532 Departments of Medicine, Obstetrics \& Gynecology, and Epidemiology, University of Michigan, Room 405E, 2800 Plymouth Road, Ann Arbor, MI 48109, USA

E-mail: cathkim@umch.edu

Received: Nov. 6, 2020; Accepted: Jan. 10, 2021
This is an Open Access article distributed under the terms of the Creative Commons Attribution Non-Commercial License (https://creativecommons.org/licenses/by-nc/4.0/) which permits unrestricted non-commercial use, distribution, and reproduction in any medium, provided the original work is properly cited. 
mended for persons with diabetes.

\section{THE MENOPAUSAL TRANSITION, CVD RISK FACTORS, AND CVD RISK}

Age at natural menopause, used interchangeably with age at the FMP, is defined as the cessation of menstruation among women who have not undergone hysterectomy or bilateral oophorectomy. Among Korean women, the age at the FMP has increased steadily over the last half-century [5], likely fueled by improvements in standard of living as well as life expectancy. Of the 12,761 participants who experienced natural menopause in the Korea National Health and Nutrition Examination Survey (KNHANES), the age at FMP advanced in younger cohorts [5]. Among women born prior to 1930, the age at the FMP was 47.9 years, whereas in women born between 1945 and 1949, the age at FMP was 50.5 years [5]. The term "perimenopause" is often loosely applied to the several years flanking the FMP, but technically is defined by menstrual irregularity according to the international Stages of Reproductive Aging Workshop (STRAW) consortium [6]. According to STRAW criteria, women begin perimenopause when their menses vary by $\geq 7$ days between consecutive cycles [6]. Women are then classified as postmenopausal when a year has passed without a menstrual period [6].

These alterations in menses are accompanied by alterations across multiple organ systems that contribute to increase risk of CVD (Fig. 1). While the menopausal transition itself is not associated with weight gain [7], women have redistribution of body fat resulting in a relative increase in visceral adiposity [8], in turn leading to unfavorable adipokine profiles [9], and subsequent insulin resistance and dyslipidemia [10]. Changes in sex hormone profiles contribute to activation of the renin-angiotensin system and abnormal endothelial factors, resulting in altered vascular reactivity and endothelial dysfunction $[11,12]$. Although not experienced by all women who transition through menopause, the increased risk of depression observed during this time [13], and sleep disturbances from vasomotor symptoms [14] may interfere with healthy lifestyle behaviors that mitigate CVD risk factors. The Study of Women's Health Across the Nation (SWAN), a longitudinal multicenter cohort of women in the United States, has assessed serial CVD risk factors, sex steroid levels, and symptoms as women transition through menopause [15]. Total cholesterol, LDL-C, and apolipoprotein B substantially increased during the time period beginning 1 year prior to the FMP and ending 1 year after the FMP [15]. This suggests that the changes in sex steroid levels that occur during the year prior to and after the FMP, particularly declines in estradiol [16], may negatively impact lipid levels. In contrast, blood pressure and glucose levels, as well as non-traditional risk factors such as inflammatory markers, increased in a linear manner around the FMP, suggesting that
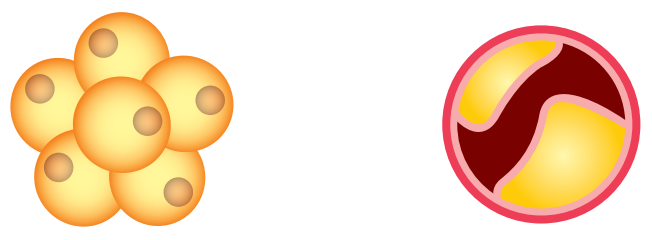

Visceral adiposity and adipokines

- Increased isulin resistance

- Dyslipidemia

- Increased inflammation

Endothelial dysfunction

- Increased angiotensin II

- Increased oxidative stress

- Increased endothelin 1

- Decreased nitric oxide synthase
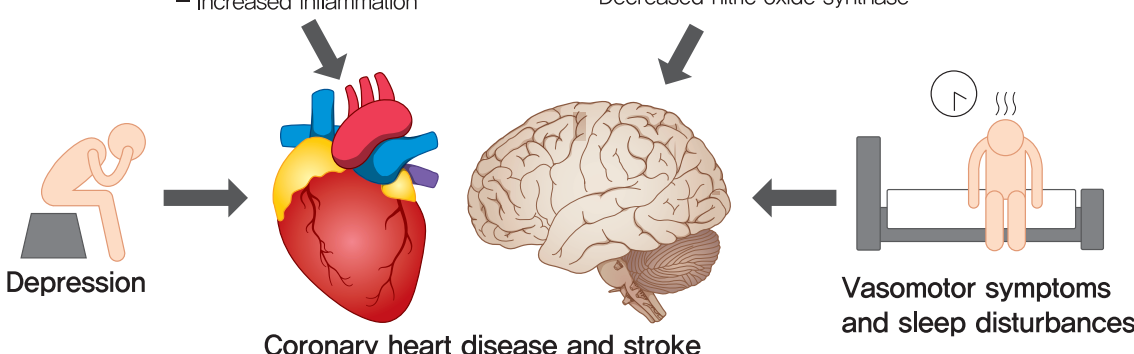

Fig. 1. Menopausal- and age-related changes in visceral adiposity and endothelial dysfunction, along with increased risk of depression, vasomotor symptoms and sleep disturbances, increase risk of coronary heart disease and stroke in midlife women. 
chronologic aging explained these worsening risk factors during mid-life [15]. Few studies have examined how CVD risk profiles change specifically women with diabetes during the menopausal transition; one study of hospitalized women with diabetes suggested that postmenopausal status was associated with poorer CVD risk factors and greater CVD risk compared to premenopausal status, although it was unclear whether this effect was independent of chronologic age and acute illness [17].

Such increases in risk factor levels are likely harmful even below cutpoints used to define diabetes, hypertension, and dyslipidemia. The Emerging Risk Factors Collaboration combined data from 102 prospective studies that collectively enrolled persons across over 30 countries (including China and Japan, but not Korea) and noted that levels of fasting plasma glucose above $100 \mathrm{mg} / \mathrm{dL}$ were linearly associated with coronary heart disease (CHD) risk [18], even among persons without diabetes. Along similar lines, analyses using data from the United Kingdom Diabetes Prevention Study (UKPDS) noted increased risk of myocardial infarction at each level of blood pressure [19] and LDL-C [20] among persons with diabetes, without evidence for a threshold effect. Such perimenopausal changes likely exacerbate the already elevated risk of atherosclerotic events in women with diabetes. Among women with diabetes, the prevalence of known CHD under the age of 45 years is less than $5 \%$ for both men and women, but prevalence rises rapidly and linearly after the age of 45 years [21]. Depending upon how $\mathrm{CHD}$ is ascertained, the ratio of $\mathrm{CHD}$ in persons with diabetes to those without diabetes varies slightly: in the U.S. National Health and Nutrition Examination Survey (NHANES), the prevalence of CHD among persons with diabetes was $29.7 \%$ compared to $9.4 \%$ among persons without diabetes [21].

\section{TRIALS OF ESTROGEN THERAPY}

The use of estrogen supplementation for women in perimenopause and postmenopause has undergone its own transition. Once widely used for chronic disease prevention, estrogen therapy is currently used for relief of vasomotor symptoms and/or symptoms due to vaginal atrophy [22]. The Women's Health Initiative (WHI) was a large United States randomized trial of estrogen therapy (with and without progestin) among women who averaged approximately 63 years of age at randomization. Women who had undergone a hysterectomy were assigned to conjugated equine estrogen alone $(n=5,310)$ versus placebo $(n=5,429)$, whereas women with an intact uterus were assigned to conjugated equine estrogen plus medroxyprogesterone $(n=8,506)$ versus placebo $(n=8,102)$ [23]. Neither estrogen therapy alone nor estrogen plus progestin therapy appeared to decrease the risk of $\mathrm{CHD}$ events and risk of stroke was increased [23]. After the study results were released in 2001, prescription of estrogen-based therapies declined to less than $10 \%$ in the United States [24]. More recent studies have examined whether estrogen use might be of greater benefit when examined over a longer time period. A 2017 systematic review examined long term risks associated with estrogen therapy, including follow-up from the WHI; due to the size of WHI, the results were heavily weighted by participants in this trial [25]. Although risk of myocardial infarction gradually declined over time, risk of stroke remained elevated over a decade after randomization [25]. WHI study results were similar among the subgroup of women with diabetes [23], and oral estrogen was actually associated with slightly lower risk of diabetes in the WHI [26]. Of note, estrogen therapy is contraindicated among women with known CVD and may be particularly risky among women with diabetes: randomization to estrogen use in women with abnormal glucose tolerance and angiographic CHD exacerbated inflammatory risk profiles and atherosclerotic progression [27], and estrogen use was associated with greater risk of myocardial infarction among women with diabetes and CHD [28].

The timing hypothesis states that estrogen therapy may prevent plaque formation without helping plaque regression [29]. Consequently, this hypothesis implies that initiation of estrogen therapy in the perimenopause or early postmenopausal period may lead to CVD benefit. Subanalysis of WHI participants $<60$ years of age, and among participants randomized to estrogen without progestin, suggested that this selected population may have derived a CHD benefit from estrogen use [30]. However, this subanalysis was not statistically powered to detect a benefit [30]. Of note, subanalysis of WHI participants $<60$ years of age who were randomized to estrogen and progestin did not suggest any such benefit [30].

Several other studies have examined the impact of estradiol or conjugated estrogen upon intermediate atherosclerotic markers such as CAC and cIMT in newly postmenopausal women [31]. The Kronos Early Estrogen Prevention Study (KEEPS) did not find different levels of CAC or CIMT in the estrogen-based therapy groups [31], and the Early Versus Late 
Intervention Trial with Estradiol (ELITE) also did not find that randomization or oral estradiol had any impact on CAC [3]. Although cIMT progression was slower in the estradiol group, the clinical significance of this was unclear as events were too few to detect differences between randomization arms [3]. A Danish study examined the impact of randomization to estradiol therapy vs. no therapy and found a lower risk of a composite outcome of death, hospital admission for heart failure, and myocardial infarction [32]. However, this trial has been criticized for lack of a placebo as well as use of an outcome that was not pre-specified [32].

In summary, estradiol supplementation does not appear to offer consistent benefit for prevention of CVD events in younger or older populations. However, in younger perimenopausal and postmenopausal women with vasomotor symptoms, such therapies do not appear to adversely increase risk of CVD and overall mortality. Thus, estradiol, particularly transdermal formulations, could be considered for treatment of symptoms including vasomotor symptoms and vaginal atrophy. Women with diabetes may be particularly vulnerable to experiencing such symptoms, since overweight and obese women are more likely to suffer than women who are not overweight [33].

\section{RISK CALCULATORS FOR CVD AND BREAST CANCER}

Perimenopausal and newly postmenopausal women with diabetes and symptoms of menopause are at high risk for adverse events with estrogen therapy if they have a history of known CVD, thromboembolic events, active liver disease, or estrogen-sensitive malignancy including breast cancer. Therefore, alternate therapies to estrogen are recommended for relief of menopausal symptoms for women with these conditions [4]. Such alternate approaches include behavioral modifications, gabapentin, selective serotonin or norepinephrine reuptake agents, and are reviewed in greater detail in other reviews [4].

In women without contraindications to estrogen therapy, risk calculators can be used to guide decision-making. Multiple CVD risk calculators or engines have been derived from large cohorts of persons with decades of follow-up, including the Korean Risk Prediction Model (KRPM) which was developed in the Korean Heart Study population [34]. Several other risk calculators are available at no-cost online, including the UKPDS engine [35]; the Pooled Cohort Equations risk engine [36]; and the Prediction for ASCVD Risk in China (China-
PAR) risk engine [37]. To our knowledge, the accuracy of these calculators has not been compared for Korean women with diabetes specifically, and thus each calculator has hypothetical benefits and limitations for estimation of risk in Korean perimenopausal or newly menopausal women with diabetes. The UKPDS calculator has the largest number of persons with type 2 diabetes mellitus [35]; the Pooled Cohort Equations risk calculator was pooled from multiple cohorts [36]; the China-PAR calculator was validated in East Asian populations [37]; and the KRPM calculator has been validated in other Korean populations [38]. Despite variations in the weighting of particular factors, the classification of persons at medium versus high risk is fairly consistent across calculators. Women with high risk of CVD events due to suboptimal levels of risk factors, family history, or age should not receive estrogen therapy. Usually, this includes women with diabetes who are older than 60 years of age, more than 10 years from their last menses, and have abnormal CVD risk factor levels [39].

Similarly, risk engines that incorporate women's reproductive histories and family histories of malignancy are available to calculate women's risk of breast cancer. Women with significantly elevated risk of breast cancer due to unfavorable family or reproductive histories should not receive estrogen therapy. The strengths and limitations of these breast cancer risk models vis-à-vis Korean women were recently summarized in 2020 [40]. To varying degrees, these engines incorporate chronologic age, family history of breast cancer, age at menarche and menopause, pregnancies and abortions, breast feeding practices, breast biopsy history and histology, use of oral contraceptives, and physical activity levels. The most extensively validated model for breast cancer prediction was originally developed by Gail and a modified version, the Breast Cancer Risk Assessment Tool (BRCAT) is available on-line [41]. However, discriminatory accuracy in Korean women has been limited, with one report noting an area under the curve (AUC) of 0.546 ( $95 \%$ confidence interval, 0.500 to 0.594 ) [42]; AUC of 0.5 suggests that the test cannot discriminate between persons with and without the condition, whereas AUC $>0.7$ is generally considered useful for risk prediction. Of note, modifications of this model based upon Korean populations of women [43] also had suboptimal AUC [42], suggesting that historical data is limited for prediction of breast cancer generally. Thus, women considering estrogen therapy should also be willing to engage in mammographic imaging and routine follow-up.

If women with diabetes are determined to be at low risk for 
CVD or malignancy using these calculators, and if women are interested in the limited use of estrogen therapy for relief of symptoms, transdermal or oral estradiol therapy can be initiated. Transdermal estradiol is generally preferred, since oral estradiol may adversely affect inflammation and coagulation profiles [44] and thromboembolic risk to a greater extent than transdermal estradiol [22]. If oral estradiol is initiated, 10-year CVD risk should be low, and oral estradiol should be avoided in women at moderate or high risk. In general, the lowest dose for relief of symptoms should be given, along with progesterone to reduce the risk of uterine cancer in women who have a uterus.

\section{HEATLHY LIFESTYLE BEHAVIORS}

In both women and men with diabetes, promotion of healthy lifestyle behaviors is the core of management of diabetes complications. These recommendations are outlined in the Table 1. The epidemiologic evidence for the benefits of healthy lifestyle behaviors is extensive. However, the impact of such behaviors in well-controlled randomized trials is limited, in part due to the strong epidemiologic evidence as well as the difficulty in achieving and maintaining such behavior changes over the length of time needed to affect chronic disease incidence. Cigarette use among women with diabetes markedly increases risk of CHD events, while cigarette cessation decreases risk of CHD events $[45,46]$. Restrictions in sodium intake $(<2,300$ and $<1,500 \mathrm{mg} /$ day in persons with hypertension), increasing fruit and vegetable intake, and avoiding excessive alcohol consumption are all associated with reduced CVD risk [47]. Other observational studies among persons with diabetes note the protective effects of greater levels of physical activity upon CVD events [48] as well as total and CVD mortality [49].

Evidence from randomized trials is less conclusive regarding the beneficial effects of physical activity and weight loss among persons with diabetes [50]. The Action for Health in Diabetes (also called Look AHEAD) trial randomized men and women with diabetes to intensive lifestyle intervention to reduce cardiovascular morbidity and mortality [50]. If weight loss goals were not achieved within 6 months, orlistat or more intensive weight loss strategies were initiated. Such weight loss goals were achieved by increasing physical activity and incorporation of a low-calorie diet with $<30 \%$ of calories from fat. No reductions in CVD morbidity and mortality were observed by randomization arm [50]. In addition to difficulty of maintain-

Table 1. Recommendations for reducing cardiovascular risk in peri- and newly postmenopausal women with diabetes

\begin{tabular}{|c|c|}
\hline Lifestyle behaviors & Additional considerations \\
\hline Smoking cessation & Limited data from randomized studies \\
\hline Weight reduction & Limited data from randomized studies \\
\hline Physical activity at least 30 minutes a day & Limited data from randomized studies \\
\hline Restrict sodium intake $<2,300 \mathrm{mg} /$ day & $<1,500 \mathrm{mg} /$ day if hypertension \\
\hline Fruit and vegetable consumption of 10 servings/day & Limited data from randomized studies \\
\hline Alcohol consumption $\leq 1$ serving per day & Limited data from randomized studies \\
\hline $\begin{array}{l}\text { Glycemia } \\
\text { A1c }<7 \% \text {, with lower targets if tolerated for microvascular disease } \\
\text { Consider SGLT-2 inhibitor or GLP-1 receptor agonist for women with } \\
\text { CVD }\end{array}$ & Higher Alc if limited life expectancy or morbidity from therapy \\
\hline $\begin{array}{l}\text { Blood pressure } \\
\text { Blood pressure }<140 / 90 \mathrm{~mm} \mathrm{Hg} \text {, with lower SBP and DBP if tolerated } \\
\text { Consider ACE inhibitor or angiotensin receptor blocker }\end{array}$ & $\begin{array}{l}\text { Higher BP if limited life expectancy or morbidity from therapy } \\
\text { Contraindicated in pregnancy }\end{array}$ \\
\hline $\begin{array}{l}\text { Cholesterol } \\
\text { Statin use for women with CVD }\end{array}$ & $\begin{array}{l}\text { No or moderate statin if low CVD risk } \\
\text { Contraindicated in pregnancy }\end{array}$ \\
\hline $\begin{array}{l}\text { Anti-platelet therapy } \\
\text { Aspirin use for women with CVD }\end{array}$ & $\begin{array}{l}\text { No use if low CVD risk } \\
\text { Clopidogrel if aspirin allergy }\end{array}$ \\
\hline
\end{tabular}

SGLT-2, sodium glucose co-transporter 2; GLP-1, glucagon-like peptide 1; CVD, cardiovascular disease; SBP, systolic blood pressure; DBP, diastolic blood pressure; ACE, angiotensin converting enzyme; BP, blood pressure. 
ing a relatively large amount of weight loss over an extended period of time, explanations for the lack of significance have included gradual loss of weight in placebo arm, along with the generally good control of risk factors and low risk of CVD events compared to non-randomized populations. However, due to concomitant improvements in hemoglobin Alc, blood pressure, functioning and quality of life, weight loss remains strongly recommended for persons with diabetes.

\section{ANTIPLATELET AND STATIN THERAPY}

Aspirin is recommended for all women with diabetes who have known CVD [51]. Perimenopausal women with diabetes and without known CVD still have elevated CVD risk compared to women without diabetes [21]. However, for these women, the risk of gastrointestinal bleeding may be higher than CVD risk particularly among younger patients. Thus, the use of the CVD risk calculators mentioned in the previous section can be applied to determine whether the risk of CVD might outweigh risk of gastrointestinal bleeding. In general, for women with diabetes who are less than 50 years of age, the risk of a CVD event is lower than the risk of gastrointestinal bleeding, and the benefits of aspirin for reduction of CVD may be less for women than for men [52]. Conversely, aspirin is recommended for women aged $\geq 50$ years with diabetes and at least one additional major risk factor (family history of premature ASCVD, hypertension, dyslipidemia, smoking, or chronic kidney disease/albuminuria) who are not at increased risk of bleeding (e.g., older age, anemia, renal disease). Aspirin therapy for primary prevention may be considered in the context of shared decision-making, which carefully weighs the cardiovascular benefits with the fairly comparable increase in risk of bleeding [51].

Lipid disorders are common among midlife persons with diabetes, and use of statins is recommended for all women with diabetes and known CVD [51]. As statins have benefits for CVD risk prevention aside from lipid levels, statin use should be considered for all women with diabetes. However, for perimenopausal women with diabetes and without known CVD, and for women with type 1 diabetes mellitus, the benefits of statin therapy are less established than for older women with type 2 diabetes mellitus. If younger women have CVD risk levels less than $5 \%$ using the aforementioned risk calculators, and women are already engaged in intensive management of other risk factors including lifestyle modification, glycemia, and blood pressure, addition of a statin could potentially be deferred until increases in risk occur [51].

\section{GLYCEMIC CONTROL}

For persons with diabetes generally, hemoglobin Alc $<7 \%$ targets are recommended with more intensive targets for specific populations, such as pregnant women [51]. Randomized trials have not found significant macrovascular benefit for persons randomized to intensive reductions in glycemia [53]. In a 2013 meta-analysis of such trials, including 18,717 participants randomized to intensive glycemic control versus 16,195 participants to conventional control, reductions in risk for microvascular disease were observed but not in CVD events or mortality [53]. Thus, tight control of A1c to levels $<7 \%$ can be attempted to reduce microvascular disease. For women in whom reduction of CVD risk is secondary to other considerations including limited life expectancy or comorbidity from intensive glycemic therapy, A1c targets can be adjusted upwards [54]. The use of specific hypoglycemic medications may have beneficial effects for CVD risk reduction, apart from degree of glycemia. Although detailed review of the pros and cons of each of these therapies is beyond the scope of this article focusing upon the menopausal transition, I mention briefly that the sodium glucose co-transporter 2 (SGLT-2) inhibitors and the glucagon-like peptide 1 (GLP-1) receptor agonists have been associated with reduced risk of CVD events among persons with diabetes, particularly for persons with a history of CVD [55].

\section{BLOOD PRESSURE}

The optimal blood pressure targets for persons with diabetes vary depending upon comorbidity burden and CVD risk. For persons with diabetes generally, a blood pressure of $<140 / 90$ $\mathrm{mm} \mathrm{Hg}$ is associated with reduction of CVD risk as well as mortality [56]. Lower blood pressures were actually associated with higher CVD risk in a meta-analysis of 49 trials including 73,738 participants with diabetes [56], while other meta-analyses suggest that more intensive lowering to targets $<130 \mathrm{~mm}$ $\mathrm{Hg}$ is associated with lower CVD risk [57]. Benefit is primarily due to reduced risk of stroke rather than overall CVD events or death. Perimenopausal and newly postmenopausal women are younger than the overall population of persons with diabetes and hypertension. These younger women may be able to toler- 
ate blood pressure reductions of $<130 \mathrm{~mm} \mathrm{Hg}$ better than older populations who tend to have significantly wider pulse pressures and have higher risk of adverse reactions to medications. Currently, a goal of at least $140 / 90 \mathrm{~mm} \mathrm{Hg}$ is recommended by most organizations, with more intensive targets as can be tolerated [51]. Use of an angiotensin converting enzyme (ACE) inhibitor protects against nephropathy and may be protective from CVD among patients with diabetes as well [58], so ACEinhibitors can be useful as first-line therapy in persons with diabetes. If ACE-inhibition cannot be tolerated, the majority of benefit of blood pressure lowering is not agent specific [59]. For these women, use of angiotensin receptor blockers, diuretics, or calcium channel blockers can be used instead.

\section{CONCLUSIONS}

The menopausal transition is a period of increased risk of atherosclerotic complications for women with diabetes, as well as increased risk for vasomotor symptoms and vaginal atrophy. Risk reduction for both CVD and menopausal symptoms can be achieved through healthy lifestyle behaviors, particularly weight reduction. Estradiol therapy for symptom relief can be guided by risk calculators for CVD and breast cancer as well as mammography. Although randomized studies have not found that lowering of blood pressure $<140 / 90 \mathrm{~mm} \mathrm{Hg}$ or A1c $<7 \%$ lowers overall CVD risk, benefits may exist for other outcomes (stroke and microvascular disease, respectively). Thus, perimenopausal and newly postmenopausal women who can tolerate risk factor lowering may benefit from aggressive risk factor lowering, but if this is limited by low life expectancy or comorbidity, higher targets are acceptable. Similarly, individualized decision-making should be used to guide use of antiplatelet agents and statins, which may be of less benefit in younger populations, particularly women beginning their menopausal transition.

\section{CONFLICTS OF INTEREST}

No potential conflict of interest relevant to this article was reported.

\section{ORCID}

Catherine Kim https://orcid.org/0000-0001-9237-0532

\section{FUNDING}

None

\section{ACKNOWLEDGMENTS}

None

\section{REFERENCES}

1. Matthews KA, Gibson CJ, El Khoudary SR, Thurston RC. Changes in cardiovascular risk factors by hysterectomy status with and without oophorectomy: study of Women's Health Across the Nation. J Am Coll Cardiol 2013;62:191-200.

2. Manson JE. The Kronos Early Estrogen Prevention Study by Charlotte Barker. Womens Health (Lond) 2013;9:9-11.

3. Hodis HN, Mack WJ, Henderson VW, Shoupe D, Budoff MJ, Hwang-Levine J, et al. Vascular effects of early versus late postmenopausal treatment with estradiol. N Engl J Med 2016;374: 1221-31.

4. de Villiers TJ, Hall JE, Pinkerton JV, Perez SC, Rees M, Yang C, et al. Revised global consensus statement on menopausal hormone therapy. Maturitas 2016;91:153-5.

5. Park CY, Lim JY, Park HY. Age at natural menopause in Koreans: secular trends and influences thereon. Menopause 2018; 25:423-9.

6. Harlow SD, Gass M, Hall JE, Lobo R, Maki P, Rebar RW, et al. Executive summary of the Stages of Reproductive Aging Workshop + 10: addressing the unfinished agenda of staging reproductive aging. J Clin Endocrinol Metab 2012;97:1159-68.

7. Guthrie JR, Dennerstein L, Dudley EC. Weight gain and the menopause: a 5-year prospective study. Climacteric 1999;2: 205-11.

8. Tchernof A, Desmeules A, Richard C, Laberge P, Daris M, Mailloux J, et al. Ovarian hormone status and abdominal visceral adipose tissue metabolism. J Clin Endocrinol Metab 2004;89:3425-30.

9. Hong SC, Yoo SW, Cho GJ, Kim T, Hur JY, Park YK, et al. Correlation between estrogens and serum adipocytokines in premenopausal and postmenopausal women. Menopause 2007; 14:835-40.

10. Carr MC. The emergence of the metabolic syndrome with menopause. J Clin Endocrinol Metab 2003;88:2404-11.

11. Moreau KL, Hildreth KL, Meditz AL, Deane KD, Kohrt WM. Endothelial function is impaired across the stages of the meno- 
pause transition in healthy women. J Clin Endocrinol Metab 2012;97:4692-700.

12. Hage FG, Oparil S. Ovarian hormones and vascular disease. Curr Opin Cardiol 2013;28:411-6.

13. Bromberger JT, Kravitz HM, Chang YF, Cyranowski JM, Brown C, Matthews KA. Major depression during and after the menopausal transition: Study of Women's Health Across the Nation (SWAN). Psychol Med 2011;41:1879-88.

14. Thurston RC, Joffe H. Vasomotor symptoms and menopause: findings from the Study of Women's Health across the Nation. Obstet Gynecol Clin North Am 2011;38:489-501.

15. Matthews KA, Crawford SL, Chae CU, Everson-Rose SA, Sowers MF, Sternfeld B, et al. Are changes in cardiovascular disease risk factors in midlife women due to chronological aging or to the menopausal transition? J Am Coll Cardiol 2009;54:236673.

16. Kim C, Harlow SD, Zheng H, McConnell DS, Randolph JF Jr. Changes in androstenedione, dehydroepiandrosterone, testosterone, estradiol, and estrone over the menopausal transition. Womens Midlife Health 2017;3:9.

17. Zhou H, Zhang C, Ni J, Han X. Prevalence of cardiovascular risk factors in non-menopausal and postmenopausal inpatients with type 2 diabetes mellitus in China. BMC Endocr Disord 2019;19:98.

18. Emerging Risk Factors Collaboration, Sarwar N, Gao P, Seshasai SR, Gobin R, Kaptoge S, et al. Diabetes mellitus, fasting blood glucose concentration, and risk of vascular disease: a collaborative meta-analysis of 102 prospective studies. Lancet 2010;375:2215-22.

19. Adler AI, Stratton IM, Neil HA, Yudkin JS, Matthews DR, Cull $\mathrm{CA}$, et al. Association of systolic blood pressure with macrovascular and microvascular complications of type 2 diabetes (UKPDS 36): prospective observational study. BMJ 2000;321: 412-9.

20. Turner RC, Millns H, Neil HA, Stratton IM, Manley SE, Matthews DR, et al. Risk factors for coronary artery disease in noninsulin dependent diabetes mellitus: United Kingdom Prospective Diabetes Study (UKPDS: 23). BMJ 1998;316:823-8.

21. Cowie CC, Casagrande SS, Menke A, Cissell MA, Eberhardt MS, Meigs JB, et al. Diabetes in America. 3rd ed. Bethesda: National Institutes of Health; 2018. Chapter 18, Heart disease and diabetes. Available from: https://www.ncbi.nlm.nih.gov/ books/NBK568001.

22. The NAMS 2017 Hormone Therapy Position Statement Advisory Panel. The 2017 hormone therapy position statement of
The North American Menopause Society. Menopause 2017; 24:728-53.

23. Rossouw JE, Anderson GL, Prentice RL, LaCroix AZ, Kooperberg C, Stefanick ML, et al. Risks and benefits of estrogen plus progestin in healthy postmenopausal women: principal results from the Women's Health Initiative randomized controlled trial. JAMA 2002;288:321-33.

24. Sprague BL, Trentham-Dietz A, Cronin KA. A sustained decline in postmenopausal hormone use: results from the $\mathrm{Na}$ tional Health and Nutrition Examination Survey, 1999-2010. Obstet Gynecol 2012;120:595-603.

25. Marjoribanks J, Farquhar C, Roberts H, Lethaby A, Lee J. Longterm hormone therapy for perimenopausal and postmenopausal women. Cochrane Database Syst Rev 2017;1:CD004143.

26. Margolis KL, Bonds DE, Rodabough RJ, Tinker L, Phillips LS, Allen $\mathrm{C}$, et al. Effect of oestrogen plus progestin on the incidence of diabetes in postmenopausal women: results from the Women's Health Initiative Hormone Trial. Diabetologia 2004; 47:1175-87.

27. Howard BV, Hsia J, Ouyang P, Van Voorhees L, Lindsay J, Silverman $\mathrm{A}$, et al. Postmenopausal hormone therapy is associated with atherosclerosis progression in women with abnormal glucose tolerance. Circulation 2004;110:201-6.

28. Ferrara A, Quesenberry CP, Karter AJ, Njoroge CW, Jacobson AS, Selby JV, et al. Current use of unopposed estrogen and estrogen plus progestin and the risk of acute myocardial infarction among women with diabetes: the Northern California Kaiser Permanente Diabetes Registry, 1995-1998. Circulation 2003; 107:43-8.

29. Grodstein F, Clarkson TB, Manson JE. Understanding the divergent data on postmenopausal hormone therapy. N Engl J Med 2003;348:645-50.

30. Manson JE, Chlebowski RT, Stefanick ML, Aragaki AK, Rossouw JE, Prentice RL, et al. Menopausal hormone therapy and health outcomes during the intervention and extended poststopping phases of the Women's Health Initiative randomized trials. JAMA 2013;310:1353-68.

31. Harman SM, Black DM, Naftolin F, Brinton EA, Budoff MJ, Cedars MI, et al. Arterial imaging outcomes and cardiovascular risk factors in recently menopausal women: a randomized trial. Ann Intern Med 2014;161:249-60.

32. Schierbeck LL, Rejnmark L, Tofteng CL, Stilgren L, Eiken P, Mosekilde L, et al. Effect of hormone replacement therapy on cardiovascular events in recently postmenopausal women: randomised trial. BMJ 2012;345:e6409. 
33. Tepper PG, Randolph JF Jr, McConnell DS, Crawford SL, El Khoudary SR, Joffe H, et al. Trajectory clustering of estradiol and follicle-stimulating hormone during the menopausal transition among women in the Study of Women's Health across the Nation (SWAN). J Clin Endocrinol Metab 2012;97:287280 .

34. Jung KJ, Jang Y, Oh DJ, Oh BH, Lee SH, Park SW, et al. The ACC/AHA 2013 pooled cohort equations compared to a Korean Risk Prediction Model for atherosclerotic cardiovascular disease. Atherosclerosis 2015;242:367-75.

35. Coleman RL, Stevens RJ, Retnakaran R, Holman RR. Framingham, SCORE, and DECODE risk equations do not provide reliable cardiovascular risk estimates in type 2 diabetes. Diabetes Care 2007;30:1292-3.

36. Goff DC Jr, Lloyd-Jones DM, Bennett G, Coady S, D'Agostino RB, Gibbons R, et al. 2013 ACC/AHA guideline on the assessment of cardiovascular risk: a report of the American College of Cardiology/American Heart Association task force on practice guidelines. Circulation 2014;129(25 Suppl 2):S49-73.

37. Yang X, Li J, Hu D, Chen J, Li Y, Huang J, et al. Predicting the 10-year risks of atherosclerotic cardiovascular disease in Chinese population: the China-PAR project (Prediction for ASCVD Risk in China). Circulation 2016;134:1430-40.

38. Bae JH, Moon MK, Oh S, Koo BK, Cho NH, Lee MK. Validation of risk prediction models for atherosclerotic cardiovascular disease in a prospective Korean community-based cohort. Diabetes Metab J 2020;44:458-69.

39. Rossouw JE, Prentice RL, Manson JE, Wu L, Barad D, Barnabei $\mathrm{VM}$, et al. Postmenopausal hormone therapy and risk of cardiovascular disease by age and years since menopause. JAMA 2007;297:1465-77.

40. Kim DY, Park HL. Breast cancer risk prediction in Korean women: review and perspectives on personalized breast cancer screening. J Breast Cancer 2020;23:331-42.

41. Gail MH, Brinton LA, Byar DP, Corle DK, Green SB, Schairer $\mathrm{C}$, et al. Projecting individualized probabilities of developing breast cancer for white females who are being examined annually. J Natl Cancer Inst 1989;81:1879-86.

42. Min JW, Chang MC, Lee HK, Hur MH, Noh DY, Yoon JH, et al. Validation of risk assessment models for predicting the incidence of breast cancer in Korean women. J Breast Cancer 2014; 17:226-35.

43. Park B, Ma SH, Shin A, Chang MC, Choi JY, Kim S, et al. Korean risk assessment model for breast cancer risk prediction. PLoS One 2013;8:e76736.
44. Salpeter SR, Walsh JM, Ormiston TM, Greyber E, Buckley NS, Salpeter EE. Meta-analysis: effect of hormone-replacement therapy on components of the metabolic syndrome in postmenopausal women. Diabetes Obes Metab 2006;8:538-54.

45. Al-Delaimy WK, Manson JE, Solomon CG, Kawachi I, Stampfer MJ, Willett WC, et al. Smoking and risk of coronary heart disease among women with type 2 diabetes mellitus. Arch Intern Med 2002;162:273-9.

46. Clair C, Rigotti NA, Porneala B, Fox CS, D’Agostino RB, Pencina MJ, et al. Association of smoking cessation and weight change with cardiovascular disease among adults with and without diabetes. JAMA 2013;309:1014-21.

47. Sacks FM, Svetkey LP, Vollmer WM, Appel LJ, Bray GA, Harsha $\mathrm{D}$, et al. Effects on blood pressure of reduced dietary sodium and the Dietary Approaches to Stop Hypertension (DASH) diet. DASH-Sodium Collaborative Research Group. N Engl J Med 2001;344:3-10.

48. Hu FB, Stampfer MJ, Solomon C, Liu S, Colditz GA, Speizer FE, et al. Physical activity and risk for cardiovascular events in diabetic women. Ann Intern Med 2001;134:96-105.

49. Hu G, Jousilahti P, Barengo NC, Qiao Q, Lakka TA, Tuomilehto J. Physical activity, cardiovascular risk factors, and mortality among Finnish adults with diabetes. Diabetes Care 2005;28: 799-805.

50. Look AHEAD Research Group, Wing RR, Bolin P, Brancati FL, Bray GA, Clark JM, et al. Cardiovascular effects of intensive lifestyle intervention in type 2 diabetes. N Engl J Med 2013;369: 145-54.

51. American Diabetes Association. 10. Cardiovascular disease and risk management: standards of medical care in diabetes-2020. Diabetes Care 2020;43(Suppl 1):S111-34.

52. Kunutsor SK, Seidu S, Khunti K. Aspirin for primary prevention of cardiovascular and all-cause mortality events in diabetes: updated meta-analysis of randomized controlled trials. Diabet Med 2017;34:316-27.

53. Hemmingsen B, Lund SS, Gluud C, Vaag A, Almdal TP, Hemmingsen $\mathrm{C}$, et al. Targeting intensive glycaemic control versus targeting conventional glycaemic control for type 2 diabetes mellitus. Cochrane Database Syst Rev 2013;(11):CD008143.

54. Riddle MC, Gerstein HC, Holman RR, Inzucchi SE, Zinman B, Zoungas S, et al. A1C targets should be personalized to maximize benefits while limiting risks. Diabetes Care 2018;41:11214.

55. Zelniker TA, Wiviott SD, Raz I, Im K, Goodrich EL, Furtado $\mathrm{RH}$, et al. Comparison of the effects of glucagon-like peptide re- 
ceptor agonists and sodium-glucose cotransporter 2 inhibitors for prevention of major adverse cardiovascular and renal outcomes in type 2 diabetes mellitus. Circulation 2019;139:202231.

56. Brunstrom M, Carlberg B. Effect of antihypertensive treatment at different blood pressure levels in patients with diabetes mellitus: systematic review and meta-analyses. BMJ 2016;352:1717.

57. Ettehad D, Emdin CA, Kiran A, Anderson SG, Callender T, Emberson J, et al. Blood pressure lowering for prevention of cardiovascular disease and death: a systematic review and meta-analysis. Lancet 2016;387:957-67.

58. Heart Outcomes Prevention Evaluation Study Investigators. Effects of ramipril on cardiovascular and microvascular outcomes in people with diabetes mellitus: results of the HOPE study and MICRO-HOPE substudy. Lancet 2000;355:253-9.

59. Emdin CA, Rahimi K, Neal B, Callender T, Perkovic V, Patel A. Blood pressure lowering in type 2 diabetes: a systematic review and meta-analysis. JAMA 2015;313:603-15. 